\title{
Effective Network Level Optimization for Bridges Maintenance
}

\section{Sofiane HADJI}

Scientific Director, SIXENSE Engineering (Vinci Group), 22-24 Rue Lavoisier - 92000 Nanterre, France

\begin{abstract}
The objective of this paper is to present an effective new methodology to optimize the maintenance costs of bridges stock. Optimization takes place at the network level and not in a project level (bridge by bridge). The dynamics of passage between bridges condition state (from 1 to 5 ) is achieved by the Markov chains probabilistic method. The Markov transition matrix is determined either by ratios of total areas and areas degraded annually, or by the resolution of an optimization problem. In the latter case, the nonlinear optimization algorithm SQP (Sequanciel Quadratic Programming) is developed. A bridge maintenance matrix is introduced in the calculation of the repair cost. The originality of our approach is to parameterize this matrix by introducing the different optimization variables of the problem. Finally, the cost function to be optimized annually is calculated and optimized by a genetic algorithm. This cost function represents the cost of maintaining the entire asset.
\end{abstract}

Keywords: Markov chain simulation; Genetic SQP optimization; Bridge deterioration modeling; Transition probability matrix, Maintenance matrix, Network level.

\section{Introduction}

An efficient maintained transportation system is a fundamental factor for the economic and social developments. For managing highway bridges, decision makers require efficient and practical decision making techniques. In a context of limited bridge management budget, it is important to determine the most effective breakdown of financial resources over the different structures of a bridge network.

Infrastructure management systems have been developed to apply the life-cycle costing approach to optimize maintenance decisions at both network and project levels and achieving network/project performance requirements under financial constraints [12, 13]. A strong interest was expressed within the managers for an objective analysis at the network level $[6,7]$ of the compromises between performance and financing. In fact, an approach at the network level initially allows us to directly have the different financial investments ratios without worrying about repairs for each bridge (project level). Once the right financial ratios have been optimized, one can scheduling maintenance for each bridge over the simulation duration

$[4,5]$.

The objective of this article is to provide infrastructure managers with a simple and effective decision-making tool capable of optimizing bridges maintenance at the macro level. The formulation is based on the probabilities of Markov chains, maintenance matrix, SQP and genetic optimization methods. The originality of our approach relates to the search for the optimum through the bridge maintenance matrix which is not predefined.

The construction of this tool requires the development of the following elements:

- Network condition rating system

- Deterioration models for prediction of bridge aging based on the condition ratings

- Cost model

- Maintenance model

- Appropriate maintenance cost function and its optimization

\section{Condition rating}

The IQOA scoring system in France (quality assessment of engineering structures) was developed to give each year a global assessment of the state of the bridge stock managed by the French Highway Agency or by private agencies. The bridge stock is assessed every 3 years (i.e., by applying IQOA inspections annually on $1 / 3$ of the total number of assets). The IQOA scoring (table 1) contain five level score 1 (the best state) to 5 
(the worst state). The definition of the condition rating is given in table below:

\section{Table 1: IQOA scoring}

\begin{tabular}{|l|l|}
\hline Rating & \multicolumn{1}{c|}{ Condition } \\
\hline 1 & $\begin{array}{l}\text { Bridge in good condition needing nevertheless } \\
\text { common maintenance }\end{array}$ \\
\hline 2 & $\begin{array}{l}\text { Bridge with defects on equipment or protection } \\
\text { elements or minor structural damages, needing } \\
\text { specialized maintenance without urgency }\end{array}$ \\
\hline 3 & $\begin{array}{l}\text { Bridge with defects on equipment or protection } \\
\text { elements or minor structural damages, needing } \\
\text { specialized maintenance with urgency on order } \\
\text { to prevent increase of defects in the structure }\end{array}$ \\
\hline 4 & $\begin{array}{l}\text { Damaged structure needing repair without } \\
\text { urgency }\end{array}$ \\
\hline 5 & Damaged structure needing repair with urgency \\
\hline
\end{tabular}

To carry out the correspondence between the various international notations systems, one can concentrate on the definition of each notation. For example, one could translate the US scoring to French one as follows:

\section{Table 2: Translation between French and US} scoring

\begin{tabular}{|l|l|}
\hline French Scoring & \multicolumn{1}{c|}{ US Scoring } \\
\hline 1 & $\begin{array}{l}\text { 9 Excellent condition } \\
8 \text { Very good condition }\end{array}$ \\
\hline 2 & 7 Good condition \\
\hline 3 & $\begin{array}{l}6 \text { Satisfactory condition } \\
5 \text { Fair condition }\end{array}$ \\
\hline 4 & $\begin{array}{l}4 \text { Poor condition } \\
3 \text { Serious condition }\end{array}$ \\
\hline 5 & $\begin{array}{l}2 \text { Critical condition } \\
1 \text { "Imminent" Failure condition }\end{array}$ \\
\hline
\end{tabular}

\section{Markov chain approach}

In a discrete-time Markov process as a stochastic process with states $X(t)$, for any $n$ time points $t_{1}, t_{2}$ $, \ldots, t_{n}$, the conditional distribution of $X\left(t_{n}\right)$ for given values of $\left\{X\left(t_{1}\right), \ldots, X\left(t_{n-1}\right)\right\}$ depends only on $X\left(t_{n-1}\right)$, which is the most recent known value. This can be stated as:

$$
\begin{gathered}
\mathrm{P}\left[X\left(t_{n}\right) \leq x_{n} \mid X\left(t_{1}\right)=x_{1,}, \ldots, X\left(t_{n}\right)=x_{n}\right]=\mathrm{P}\left[X\left(t_{n}\right) \leq\right. \\
\left.x_{n} \mid X\left(t_{1}\right)=x_{1}\right] .
\end{gathered}
$$

Bridge condition decays with time (year) and can be considered as discrete condition states at certain time intervals $[9,10,11]$. Thus, Markov chains could be the proper tool to model the bridge deterioration process. As the bridge condition is usually evaluated through several rating levels, the transition probabilities should be expressed as a matrix [P], called the transition probability matrix. The five bridge condition ratings (from 1 to 5) can be defined as five Markovian states with each condition rating corresponding to one of the five states. The matrix [P] denotes the transition probability from state $i$ to state $j$ during time $t$, as shown below:

$$
\left\{\begin{array}{l}
P^{t, t+1}=\left[\begin{array}{lllll}
p_{11}^{t, t+1} & p_{12}^{t, t+1} & p_{13}^{t, t+1} & p_{14}^{t, t+1} & p_{15}^{t, t+1} \\
p_{21}^{t, t+1} & p_{22}^{t, t+1} & p_{23}^{t, t+1} & p_{24}^{t, t+1} & p_{25}^{t, t+1} \\
p_{31}^{t, t+1} & p_{32}^{t, t+1} & p_{33}^{t, t+1} & p_{34}^{t, t+1} & p_{35}^{t, t+1} \\
p_{41}^{t, t+1} & p_{42}^{t, t+1} & p_{43}^{t, t+1} & p_{44}^{t, t+1} & p_{45}^{t, t+1} \\
p_{51}^{t, t+1} & p_{52}^{t, t+1} & p_{53}^{t, t+1} & p_{54}^{t, t+1} & p_{55}^{t, t+1}
\end{array}\right] \\
p_{i j}^{t, t+1} \geq 0 \quad i, j \in(1 ; 5) \\
\sum_{j=1}^{5} p_{i j}^{t, t+1}=1 \\
\quad i \in(1 ; 5)
\end{array}\right.
$$

Notice that the under diagonal values represent the actual maintenance activities while the over diagonal values are linked to the degradation of the structure. Two kinds of deterioration process can be modeled using the database, natural decay or "do nothing" under routine maintenance or minor repair and conventional recoverable decay with medium or major repair as well as reconstruction. The two situations are modelled using the two transitions matrices:

(i) Modeling with natural decay or "do nothing"

$$
P^{t, t+1}=\left[\begin{array}{ccccc}
p_{11}^{t, t+1} & 1-p_{11}^{t, t+1} & 0 & 0 & 0 \\
0 & p_{22}^{t, t+1} & 1-p_{22}^{t, t+1} & 0 & 0 \\
0 & 0 & p_{33}^{t, t+1} & 1-p_{33}^{t, t+1} & 0 \\
0 & 0 & 0 & 0 & 1-p_{44}^{t, t+1} \\
0 & 0 & 0 & 0 & 1
\end{array}\right]
$$

To obtain pure degradation, free of any maintenance strategy, each term in row $i$ and column $j$ under the main diagonal is set to 0 , and its previous value is added to the main diagonal term.

(ii) Modeling with actual maintenance activities

$$
P^{t, t+1}=\left[\begin{array}{ccccc}
p_{11}^{t, t+1} & 1-p_{11}^{t, t+1} & 0 & 0 & 0 \\
p_{21}^{t, t+1} & p_{22}^{t, t+1} & p_{23}^{t, t+1} & 0 & 0 \\
p_{31}^{t, t+1} & p_{32}^{t, t+1} & p_{33}^{t, t+1} & p_{34}^{t, t+1} & 0 \\
p_{41}^{t, t+1} & p_{42}^{t, t+1} & p_{43}^{t, t+1} & p_{44}^{t, t+1} & p_{45}^{t, t+1} \\
p_{51}^{t, t+1} & p_{52}^{t, t+1} & p_{53}^{t, t+1} & p_{54}^{t, t+1} & p_{55}^{t, t+1}
\end{array}\right]
$$


To simplify the transition matrix, one could take the assumption that deterioration will not take place in the form of skipping a condition state.

The approach proposed in this section is used to determine transition matrices from an inspection database during some years. Instead of examining repartition by bridges age for a particular year and deduce then the transition matrix, the overall breakdown in condition states with each year is considered. The vector state $q(t)=\left\lfloor\begin{array}{lllll}q_{1}^{t} & q_{2}^{t} & q_{3}^{t} & q_{4}^{t} & q_{5}^{t}\end{array}\right\rfloor$ include breakdown per year of the five-condition rating. For example, from database, the vector state $q=[0.2,0.3,0.28$, $0.15,0.07]$ means that the bridge stock is composed by $20 \%$ of state $1,30 \%$ of state $2,28 \%$ of state $3,15 \%$ of state 4 and $7 \%$ of state 5 . The goal is then determining the evolution of this vector over time. The matrix's values keep the same as the values of the general matrix (1). Therefore, if the initial bridge condition vector $q(0)$ is known, the future condition after $t$ time intervals can be obtained by the following equations, where $q(t)$ at time $t$, is the condition state vector:

$$
\left\{\begin{aligned}
q(t)= & q(t-1) \times P \\
& o r \\
q(t)= & q(0) \times P^{t}
\end{aligned}\right.
$$

$q(0)$ is the initial bridge condition and $q(t-1)$ the bridge condition at time $(t-1)$. One could also calculate the condition rating number at time $t, r(t)$ of the bridge stock as follow:

$$
\left\{\begin{array}{c}
r(t)=q(t-1) \times P \times R^{T} \\
r(t)=q(0) \times P^{t} \times R^{T} \\
R=\left[\begin{array}{lllll}
1 & 2 & 3 & 4 & 5
\end{array}\right]
\end{array}\right.
$$

Where $R^{T}$ is the transpose of $R$

\section{Markov transition matrix calculation}

The transition probability matrix is the key of the Markov chain model and is commonly obtained by statistical data of bridge conditions. Two methods can be used to calculate transition probability matrix, the regression method based on nonlinear optimization [2,3] and the percentage prediction method [4].

\subsection{Regression based optimization approach}

The regression-based optimization method estimates transition probabilities by solving the nonlinear optimization problem that minimizes the sum of absolute differences between the regression curve that best fits the condition data and the conditions predicted using the Markovchain model. The objective function and the constraints of this optimization problem can be formulated as follows:

$$
\left\{\begin{array}{l}
\text { Minimize } \sum_{t=1}^{N}\|q(t+1)-q(t) . P\| \\
\text { Subject to: } 0 \leq P_{i j} \leq 1 \text { for } i, j=1,2, \ldots, N \\
\quad \sum_{j} P_{i j}=1
\end{array}\right.
$$

where $N$ is the number of inspection data used in the minimization problem and $q(t)$ the vector states. The vector $\left\langle\mathrm{x}_{1}, \mathrm{x}_{2}, \mathrm{x}_{3}, \mathrm{x}_{4}\right\rangle$ contain the four optimization variables which correspond to the transition matrix modeling with natural decay:

$$
P=\left[\begin{array}{ccccc}
x_{1} & 1-x_{1} & 0 & 0 & 0 \\
0 & x_{2} & 1-x_{2} & 0 & 0 \\
0 & 0 & x_{3} & 1-x_{3} & 0 \\
0 & 0 & 0 & x_{4} & 1-x_{4} \\
0 & 0 & 0 & 0 & 1
\end{array}\right]
$$

The SQP (Sequential Quadratic Programming) algorithm is used to solve this nonlinear problem. This algorithm is one of the most effective methods for nonlinearly constrained optimization problems. The method generates steps by solving quadratic subproblems. SQP is well-suited to solving problems with significant nonlinearities. The method can be viewed as a generalization of Newton's method for unconstrained optimization in that it finds a step away from the current point by minimizing a quadratic model of the problem. The SQP algorithm replaces the objective function with the quadratic approximation and the constraint functions by linear approximations.

\subsection{Percentage prediction approach}

There are two variations possible for this approach. The first one is based on state transition index and the second on surface transition.

State transition :

$P_{i, j}=n_{i, j} / n_{i}$

Where: 
$n_{i, j}=$ number of transitions from state $i$ to state $j$ within a given time period,

$n_{i}=$ total number of bridges in state $i$ before the transition.

\section{Surface transition :}

$P_{i, j}=S i, j / S i$

where:

$S_{i, j}=$ surface of bridges with transitions from state $i$ to state $j$ within a given time period,

$S_{i}=$ total surface of bridges in state $i$ before the transition.

\section{Cost matrix}

Maintenance costs require the introduction of repair costs. These costs are defined via a matrix [C] which represents the repair amounts to move from one state to another.

$C=\left[\begin{array}{ccccc}0 & 0 & 0 & 0 & 0 \\ 1 & 0 & 0 & 0 & 0 \\ c_{31} & c_{32} & 0 & 0 & 0 \\ c_{41} & c_{42} & c_{43} & 0 & 0 \\ c_{51} & c_{52} & c_{53} & c_{54} & 0\end{array}\right]$

The cost reference is the one moving a bridge from state 2 to state 1 .

\section{Maintenance matrix}

To model the effect of bridge repairs, one must introduce the bridge maintenance matrix [M]. This matrix represents the impact of each maintenance alternative on the condition of the bridges and represent the repair policy. A typical maintenance matrix $[\mathrm{M}]$ is presented as follow:

$M=\left[\begin{array}{ccccc}1 & 0 & 0 & 0 & 0 \\ m_{21} & 1-m_{21} & 0 & 0 & 0 \\ m_{31} & m_{32} & 1-m_{31}-m_{32} & 0 & 0 \\ m_{41} & m_{42} & m_{43} & 1-m_{41}-m_{42}-m_{43} & 0 \\ m_{51} & m_{52} & m_{53} & m_{54} & 1-m_{51}-m_{52}-m_{53}-m_{54}\end{array}\right]$

The maintenance matrix is a special type of matrix with several desirable properties that make it easy to process. This matrix adheres to the following rules:

1. All maintenance matrices are square, with the number of rows and the number of columns both equal to the number of possible condition states.
2. Only the main diagonal and the lower triangle of the matrix can have non-zero values. This is another way of saying that there can be only movement from any condition state to a better state in a maintenance model.

\section{No elements of the matrix may be negative.}

4. All rows of the matrix must separately sum to $100 \%$. In other words, the maintenance matrix must account for all possible transitions.

5. Because of the combination of these rules, the upper left corner element must be $100 \%$. We can't do better than 1 scoring.

Each row of the matrix $[\mathrm{M}]$ contains a maintenance strategy.

For example, for each year, the repair policy replacing $20 \%$ of

The bridges in condition 3 and 10\% of the bridges in condition

4 moving to condition 2 can be modeled with the following

Matrix:

$M=\left[\begin{array}{ccccc}1 & 0 & 0 & 0 & 0 \\ 0 & 1 & 0 & 0 & 0 \\ 0.2 & 0 & 0.8 & 0 & 0 \\ 0 & 0.1 & 0 & 0.9 & 0 \\ 0 & 0 & 0 & 0 & 1\end{array}\right]$

The combined effect of natural deterioration ([P] matrix in

equation $1 \mathrm{~b}$ ) and repair policy can be expressed as:

$$
q(t+1)=q(t) \times P \times M
$$

And the expected value of the maintenance cost corresponding

cost can be expressed as:

$$
\operatorname{Cost}(t+1)=q(t) \times P \times M \times C
$$

This approach will be used to build the new model for optimizing maintenance budgets.

\section{Optimization maintenance strategies}

From a review of the literature, most of maintenance optimization models, that combines the use of Markov-chain models and optimization algorithms use a set of predefined maintenance scenarios to solve the problem at the network 
level. The predefined scenarios can give priority either to preventive or corrective actions, or both, with a view to controlling the budget and to ensuring the preservation of the asset. It is computationally practical for a network with a large number of bridges, which is the case of most infrastructure networks.

Unlike the other existing methods cited in the above paragraph, our new approach consists in looking for, every year, all the possible maintenance scenarios allowing optimizing the repair cost of the bridges. This approach at the network level is interesting because it makes it possible to present financial managers with optimized maintenance cost ratios over the duration of the simulation without worrying about the maintenance of each bridge or generating a specific work plan. Another advantage for this method is the infinitely smaller computation time compared to its equivalent of a project level approach. In fact, the number of optimization variables does not depend on the size of the asset (i.e. the number of bridges) but only on the number of groups of defined bridges.

The matrix $[\mathrm{P}]$ determined in the previous section makes possible to determine precisely the way the bridges conditions rating is going to evolve. The matrix $[\mathrm{M}]$ above allows to introduce maintenance policy for the bridge asset. The aim is now to optimize the maintenance strategies from an economical

point of view with keeping a good serviceability for road users.

The parameters of the proposed formulation are defined as follows:

G: number of bridges groups, for example: concrete, steel, prestressed concrete, masonry, ...

Qg: total quantity of bridges in group $g$

For each group, a cost matrix $\left[C_{g}\right]$ is defined. For example, the term $C_{51, g}$ represent the unit costs to move from a bridge in state 5 to a bridge in state 1 on the facilities in group $g$. (these unit costs have to be adjusted for inflation when long planning horizons are used).

$$
C_{g}=\left[\begin{array}{ccccc}
0 & 0 & 0 & 0 & 0 \\
1 & 0 & 0 & 0 & 0 \\
c_{31, g} & c_{32, g} & 0 & 0 & 0 \\
c_{41, g} & c_{42, g} & c_{43, g} & 0 & 0 \\
c_{51, g} & c_{52, g} & c_{53, g} & c_{54, g} & 0
\end{array}\right]
$$

For each group, a transitions matrix $\left[\mathrm{P}_{\mathrm{g}}\right]$ is defined with a natural decay modeling.

$$
P_{g}=\left[\begin{array}{ccccc}
p_{11, g} & 1-p_{11, g} & 0 & 0 & 0 \\
0 & p_{22, g} & 1-p_{22, g} & 0 & 0 \\
0 & 0 & p_{33, g} & 1-p_{33, g} & 0 \\
0 & 0 & 0 & p_{44, g} & 1-p_{44, g} \\
0 & 0 & 0 & 0 & 1
\end{array}\right]
$$

For each group, a maintenance matrix $\left[\mathrm{M}_{\mathrm{g}}\right]$ is defined. The maintenance matrix contains the unknowns of the problem to solve and represent the repair policy for each group and each year of the simulation. There are ten optimization variables per bridge group.

$$
M_{g}=\left[\begin{array}{ccccc}
1 & 0 & 0 & 0 & 0 \\
x_{1, g} & 1-x_{1, g} & 0 & 0 & 0 \\
x_{2, g} & x_{3, g} & 1-x_{2, g}-x_{3, g} & 0 & 0 \\
x_{4, g} & x_{5, g} & x_{6, g} & 1-x_{4, g}-x_{5, g}-x_{6, g} & 0 \\
x_{7, g} & x_{8, g} & x_{9, g} & x_{10, g} & 1-x_{7, g}-x_{8, g}-x_{9, g}-x_{10, g}
\end{array}\right]
$$

\section{First problem to solve: Cost minimization approach}

The first optimization problem consists to minimize every year the sum of the maintenance cost of all the bridges groups while keeping the condition of every group at any time above a predefined threshold value. The constraints are on the vector state $q(t)$ whose certain components must be more $q_{\text {inf }}$ and others less than $q_{\text {sup }}$. The optimization problem can be formulated as follows:

Minimize $\sum_{g=1}^{G} \sum_{q=1}^{Q_{g}} q(t) P_{g} M_{g} C_{g}$

Subject to: $q_{\text {inf }} \leq q(t+1) \leq q_{\text {sup }}$

The target values $q_{\text {inf }}$ et $q_{\text {sup }}$ contains the percentages of facilities whose condition is equal to or higher than a given condition state and are used to control quality of the asset. In general, the standard values are listed in the table below (table 3) but are user defined by facility managers:

Table 3: Example of target values for the states rating

\begin{tabular}{|c|c|c|}
\hline Index & $\boldsymbol{q}_{\text {inf }}$ & $\boldsymbol{q}_{\text {sup }}$ \\
\hline 1 & $15 \%$ & $\mathrm{x}$ \\
2 & $50 \%$ & $\mathrm{x}$ \\
3 & $\mathrm{x}$ & $30 \%$ \\
\hline
\end{tabular}




\begin{tabular}{|c|c|c|}
4 & $\mathrm{x}$ & $10 \%$ \\
5 & $\mathrm{x}$ & $1 \%$ \\
\hline
\end{tabular}

A heuristic method based on the well-known genetic algorithm was used to solve the model. The principle of the method is as follows: A population of chains (called chromosomes) which encode candidate solutions to an optimization problem evolves towards better solutions. Finally, the algorithm ends once either a maximum number of generations has been produced, or a satisfactory fitness level has been reached for the population.

\section{Second problem to solve: Quality maximization approach}

Another approach is to fix a budget $B_{t}$ for each year and try to maximize the quality of the asset by combining different scenarios of maintenance actions while respecting the constraints. In this case, the objective function tends to maximize the average network condition given the annual budget constraints.

$$
\left\{\begin{array}{l}
\text { Maximize } \sum_{g=1}^{G} \sum_{q=1}^{Q_{g}} q(t) P_{g} M_{g} \\
\text { Subject to: } \\
\sum_{g=1}^{G} \sum_{q=1}^{Q_{g}} q(t) P_{g} M_{g} C_{g} \leq B_{t} \\
q_{\text {inf }} \leq q(t+1) \leq q_{\text {sup }}
\end{array}\right.
$$

This approach is more practical for the bridge manager who often knows exactly how much he can spends each year for the maintenance and whose interest is to know how to allocate the funds in a best way. A genetic algorithm was also used to solve this problem.

\section{Application}

The data that support the findings of this study are openly available at: https://www.fhwa.dot.gov/bridge/nbi/ascii.cfm.

The datasets represent bridge data submitted annually to FHWA (Federal Highway Administration) by the States, Federal agencies, and Tribal governments in accordance with the National Bridge Inspection Standards and the Recording and Coding Guide for the Structure Inventory and Appraisal of the Nations Bridges. The data is published on this website at the end of each calendar year.
Data from the State of Indiana [8] was chosen for the large size of its bridges network $(15,000$ bridges shared in 6 groups). It should be noted that the study presented here does not reflect the actual maintenance policy in terms of costs for the Indiana state. This simulation was only carried out to demonstrate the relevance of the methodology and the reduced simulation time for a large bridges park. The National Bridge Inventory (NBI) dataset for the Indiana state was analyzed to demonstrate the proposed model. In the NBI dataset, the records for each bridge include a wealth of information, each identified by an item number. The data history for each bridge goes from year 1992 until year 2018. The characteristics of this network are given in the following tables 4 and 5:

Table 4: Indiana bridges group

\begin{tabular}{|l|c|c|}
\hline \multicolumn{1}{|c|}{$\begin{array}{c}\text { Material \& } \\
\text { structure type }\end{array}$} & $\begin{array}{c}\text { Number of } \\
\text { bridges }\end{array}$ & $\begin{array}{c}\text { \% } \\
\text { of } \\
\text { bridges }\end{array}$ \\
\hline Concrete & 2155 & 14.8 \\
Concrete continuous & 2339 & 16.1 \\
Steel & 2261 & 15.5 \\
Steel continuous & 1858 & 12.8 \\
Prestressed concrete & 4506 & 31.0 \\
Prestressed concrete & 1412 & 9.8 \\
continuous & $\mathbf{1 4 5 3 1}$ & $\mathbf{1 0 0}$ \\
Total
\end{tabular}

Actions are taken for extracting information from the NBI records for Indiana and filtering the bridges into six subgroups as shown in table 4 . Only common structural materials are considered, excluding wood, masonry, or aluminum structures from the study. Condition Ratings is used to evaluate the bridge condition numerically, ranging from 0 to 9 . A translation to a scoring from 1 to 5 is operate following rules of table 2 .

Table 5: Indiana characteristics for six group bridges network

\begin{tabular}{|c|c|c|c|}
\hline $\begin{array}{c}\text { Total } \\
\text { length }\end{array}$ & $\begin{array}{c}\text { Average } \\
\text { length }\end{array}$ & $\begin{array}{c}\text { Total bridges } \\
\text { deck surface }\end{array}$ & $\begin{array}{c}\text { Average } \\
\text { bridges deck } \\
\text { surface }\end{array}$ \\
\hline $\begin{array}{c}493 \\
\mathrm{~km}\end{array}$ & $34 \mathrm{~m}$ & $6011005 \mathrm{~m}^{2}$ & $414 \mathrm{~m}^{2}$ \\
\hline
\end{tabular}

Fig. 1 shows the characteristics of the asset in term of age in $2018.75 \%$ of the bridge network has less than 75-year-old. 


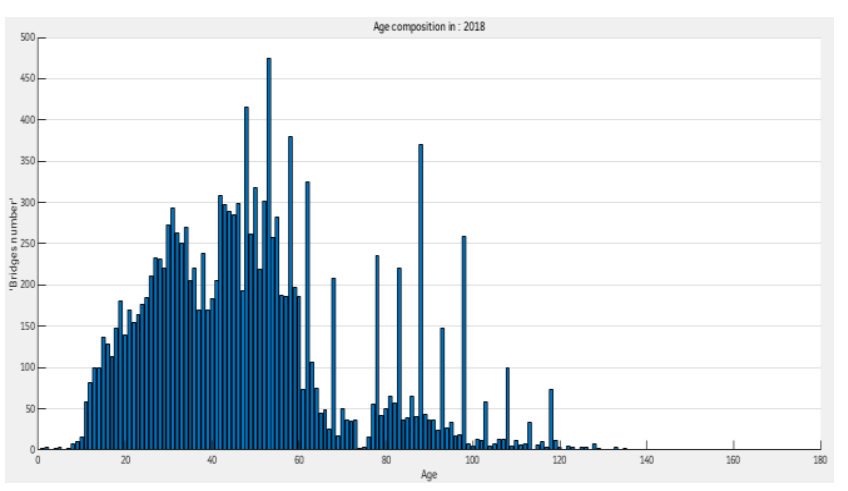

Fig. 1: Age composition of all bridges group in 2018 for Indiana

Fig. 2 show the historical rating evolution from 1992 to 2018. One specify that the indicators scoring vary from 1 to 5 . Two kind of evolution rating is considered: The first type is based on the evolution of the indicators by their number as a function of time (from 1992 to 2018). For each year, the number of bridges is determined in relation to its indicator. The second type considers the evolution of the indicators scoring by associating the corresponding area with each bridge deck.

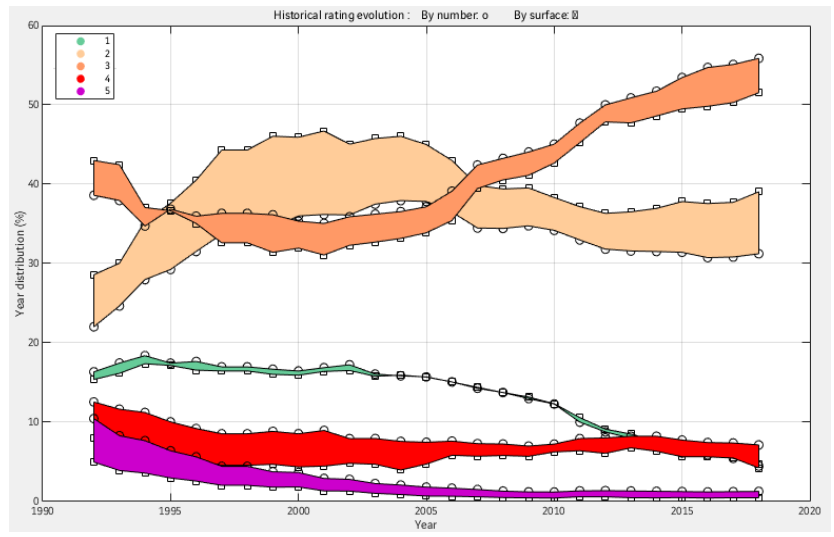

Fig. 2: Historical rating evolution by number and by surface for Indiana

This means that bridges with index 2 for example, have a larger area than the average and are therefore more represented by their areas than by their numbers. In the following, one will therefore work on the rating of bridges in terms of area. The explanation can be given in the following example: The vector state $q=[0.2,0.3,0.28,0.15$, 0.07] means that the bridge deck surface is composed by $20 \%$ of state $1,30 \%$ of state $2,28 \%$ of state $3,15 \%$ of state 4 and $7 \%$ of state 5 .

\section{Markov probability matrices}

The calculation of the transition probability matrices uses the historical data from the year 1992 to the year 2018. Modeling with natural decay is adopted by following the equation 1c.
Specific data processing has been carried out to calculate those transition matrices: The deterioration models were developed for bridge decks with no improvement works have been undertaken in between. Therefore, inspection records for bridge deck element, after repair and reconstruction actions, have been excluded from analysis data base. Also, bridge deck element whose condition rating had been improved over the years were removed from data base.

In the circumstance of natural decay, only four transition probabilities are needed for each bridge group which gives 24 transition probabilities for all the groups. Each matrix was calculated by averaging the matrices calculated between two time steps $t$ and $t+1$. In total, between 1992 and 2018 , each matrix representing a group represents the average of 26 matrices.

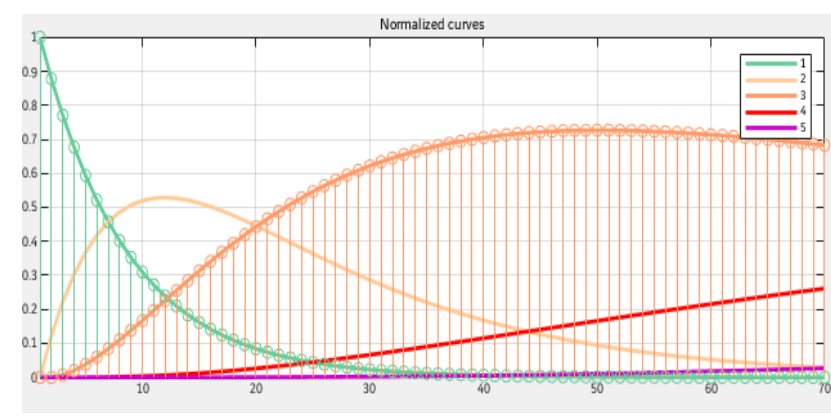

$$
P_{g 1}=\left[\begin{array}{ccccc}
0.878 & 0.122 & 0 & 0 & 0 \\
0 & 0.941 & 0.059 & 0 & 0 \\
0 & 0 & 0.992 & 0.008 & 0 \\
0 & 0 & 0 & 0.996 & 0.004 \\
0 & 0 & 0 & 0 & 1
\end{array}\right]
$$

Fig. 3: Transition matrix and condition state distribution with age for Concrete group

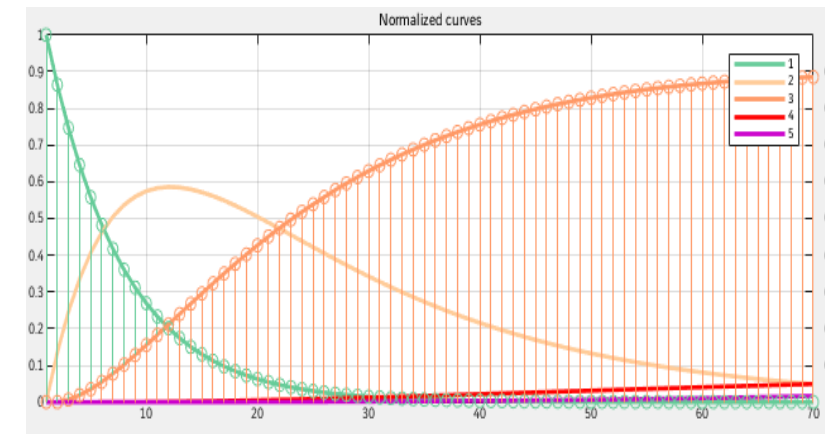

$$
P_{g 2}=\left[\begin{array}{ccccc}
0.864 & 0.136 & 0 & 0 & 0 \\
0 & 0.951 & 0.049 & 0 & 0 \\
0 & 0 & 0.998 & 0.002 & 0 \\
0 & 0 & 0 & 0.988 & 0.012 \\
0 & 0 & 0 & 0 & 1
\end{array}\right]
$$


Fig. 4: Transition matrix and condition state distribution with age for Continue-Concrete group

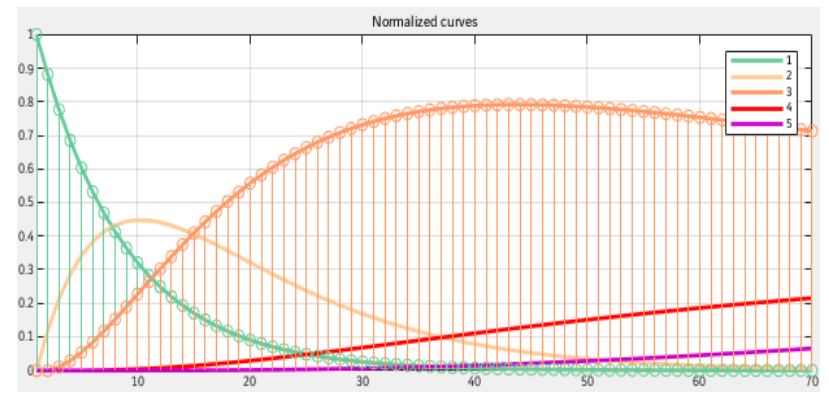

$P_{g 3}=\left[\begin{array}{ccccc}0.881 & 0.119 & 0 & 0 & 0 \\ 0 & 0.912 & 0.088 & 0 & 0 \\ 0 & 0 & 0.993 & 0.007 & 0 \\ 0 & 0 & 0 & 0.990 & 0.010 \\ 0 & 0 & 0 & 0 & 1\end{array}\right]$

Fig. 5: Transition matrix and condition state distribution with age for Steel group

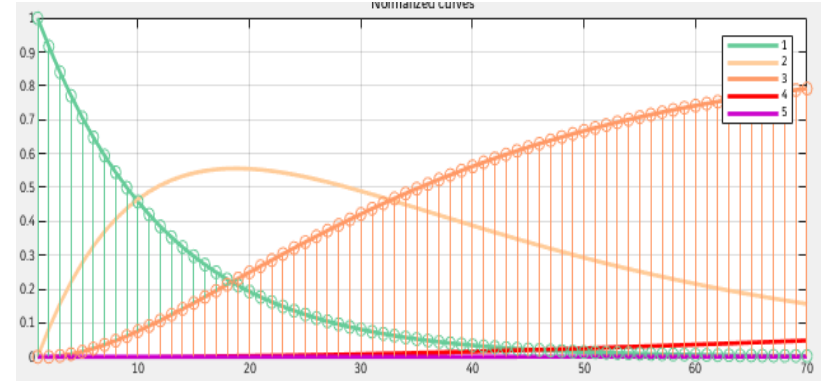

$$
P_{g 4}=\left[\begin{array}{ccccc}
0.917 & 0.083 & 0 & 0 & 0 \\
0 & 0.967 & 0.033 & 0 & 0 \\
0 & 0 & 0.998 & 0.002 & 0 \\
0 & 0 & 0 & 0.990 & 0.001 \\
0 & 0 & 0 & 0 & 1
\end{array}\right]
$$

Fig. 6: Transition matrix and condition state distribution with age for Continue-Steel group

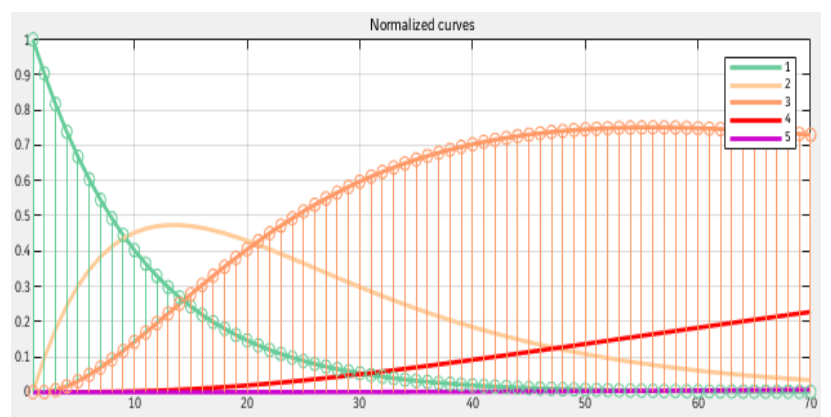

$$
P_{g 5}=\left[\begin{array}{ccccc}
0.904 & 0.096 & 0 & 0 & 0 \\
0 & 0.940 & 0.060 & 0 & 0 \\
0 & 0 & 0.994 & 0.006 & 0 \\
0 & 0 & 0 & 0.999 & 0.001 \\
0 & 0 & 0 & 0 & 1
\end{array}\right]
$$

Fig. 7: Transition matrix and condition state distribution with age for Prestressed group

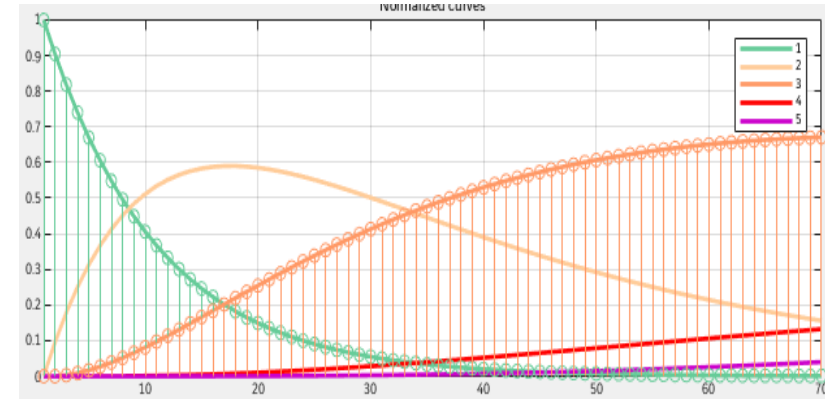

$$
P_{g 6}=\left[\begin{array}{ccccc}
0.905 & 0.095 & 0 & 0 & 0 \\
0 & 0.968 & 0.032 & 0 & 0 \\
0 & 0 & 0.994 & 0.006 & 0 \\
0 & 0 & 0 & 0.988 & 0.012 \\
0 & 0 & 0 & 0 & 1
\end{array}\right]
$$

Fig. 8: Transition matrix and condition state distribution with age for Continue-Prestressed group

The above curves (fig. 3 to 8 ) describe networklevel bridge deterioration model output (condition state distribution), which is the percentage of bridges surface in each condition state along with age (1 to 5 are the percentage curves of condition states 1-5) for the selected group. According to the curve 1 , it is clear that the condition state 1 value approaches 0 (well under 5\%) after 30 years of age. Between ages 5 and 20, 2 is highest compared with the other condition states. The percentage of 4 components continuously increases with time. Curve 5 does not vary greatly and remains close to 0 , which implies that almost all the bridges are repaired before reaching this last level of deterioration.

\section{Cost matrices}

The unit costs to move from a bridge in state $i$ to a bridge in state $j$ were estimated for example in France for public owner are given in the following matrix:

$$
C=110.64 € .\left[\begin{array}{ccccc}
0 & 0 & 0 & 0 & 0 \\
1 & 0 & 0 & 0 & 0 \\
2.93 & 2.63 & 0 & 0 & 0 \\
3.94 & 3.55 & 3.15 & 0 & 0 \\
26.65 & 5.09 & 4.07 & 3.56 & 0
\end{array}\right]
$$


It is specified that this cost matrix is just an example to validate the methodology and does not represent the reality of the costs practiced in the Indiana state. For simplification reasons, the same cost matrix is assigned to all the bridge groups studied. The reality is different, but the calculation procedure remains the same.

\section{Scenarios optimizations}

Before calculating optimal scenarios, three predefined scenarios must be analyzed to obtain orders of magnitude of the ratios to be optimized. The simulation duration is 15 years for all scenarios. The steps for calculating these predefined scenarios are as follows:

Scenario 1: in this case, one do nothing, so there is no maintenance at all. The maintenance strategy matrix $[\mathrm{M}]$ is then equal to:
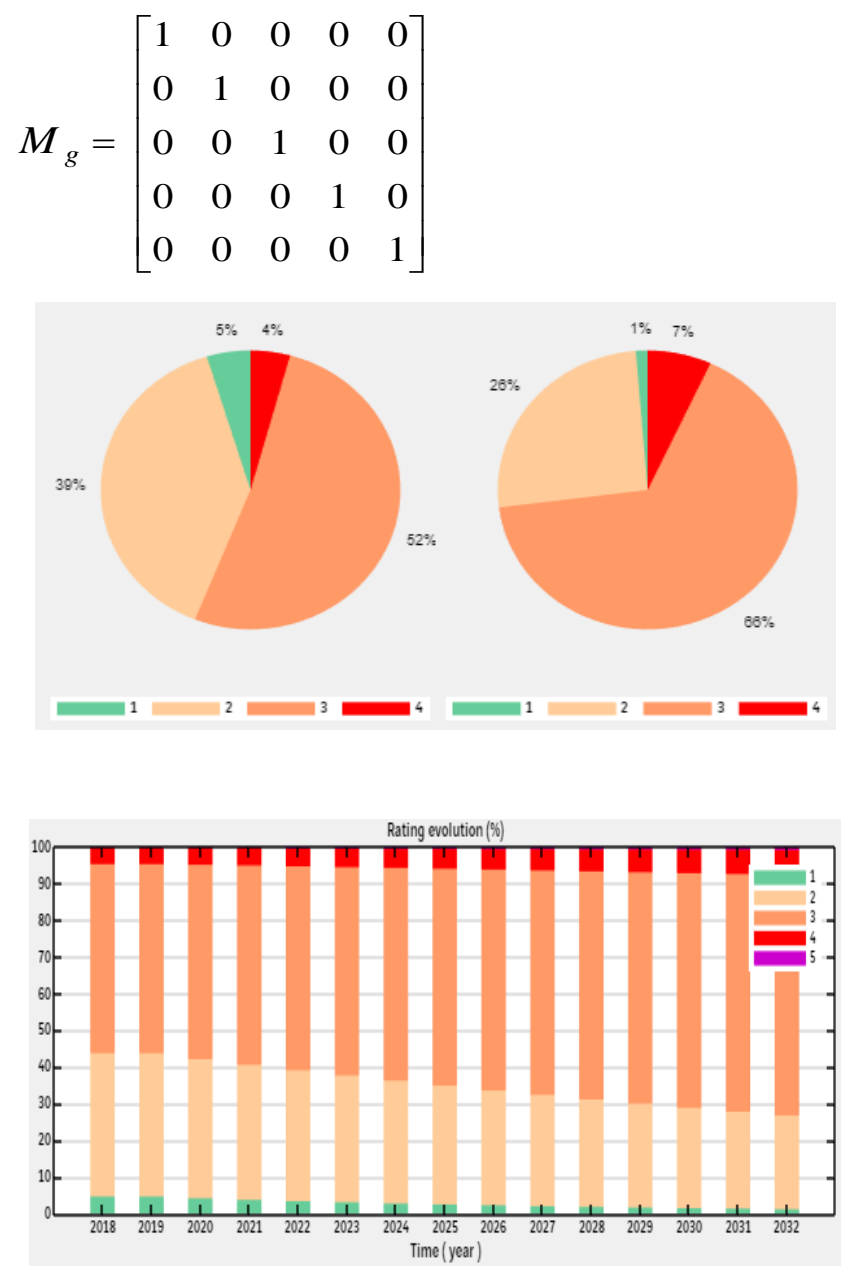

Fig. 9: Rating (\%) before and after simulation and Rating evolution

The total cost per year is zero (table 6) since there is no maintenance and the average global rating (1 the best to 5 the worst) goes from 2.57 to 2.81 (figure 9).
Table 6: Cost of maintenance per $\mathrm{m}^{2}$ of deck for the six groups for predefined scenario 1

\begin{tabular}{|c|ccccccc|}
\hline & 1 & 2 & 3 & 4 & 5 & 6 & Average \\
\cline { 2 - 7 } Cost & 0 & 0 & 0 & 0 & 0 & 0 & 0 \\
$€ / \mathrm{m}^{2}$ & & & & & & & \\
\hline
\end{tabular}

Scenario 2: one calculates for each year $t+1$, the costs to systematically restore the indicators to their levels in year $t$. One Keep all rating index constant.

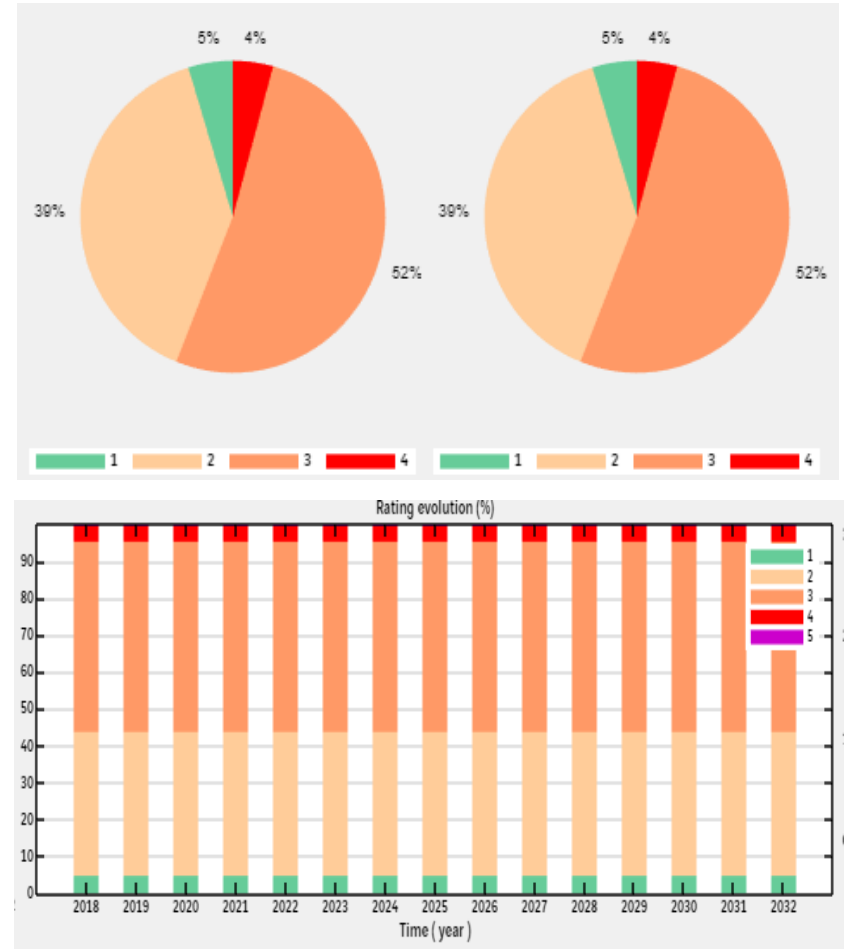

Fig. 10: Rating (\%) before and after simulation and Rating evolution

The total cost per year for maintenance is equal to $35.9 \mathrm{M} € /$ year and the average cost per $\mathrm{m}^{2}$ is equal to $83.7 € / \mathrm{m}^{2}$ (table 7 ). The average global rating (figure 10) keep the same value to 2.57.

Table 7: Cost of maintenance per $\mathrm{m}^{2}$ of deck for the six groups for predefined scenario 2

\begin{tabular}{|c|ccccccc|}
\hline & 1 & 2 & 3 & 4 & 5 & 6 & Average \\
\cline { 2 - 8 } Cost & 72 & 76 & 115 & 72 & 100 & 94 & 83.7 \\
$€ / \mathrm{m}^{2}$ & & & & & & & \\
\hline
\end{tabular}

Scenario 3: one calculate for each year $t+1$, the costs to systematically return the indicators to level 1 . In this case the maintenance strategy matrix $[\mathrm{M}]$ is equal to: 
$M_{g}=\left[\begin{array}{lllll}1 & 0 & 0 & 0 & 0 \\ 1 & 0 & 0 & 0 & 0 \\ 1 & 0 & 0 & 0 & 0 \\ 1 & 0 & 0 & 0 & 0 \\ 1 & 0 & 0 & 0 & 0\end{array}\right]$
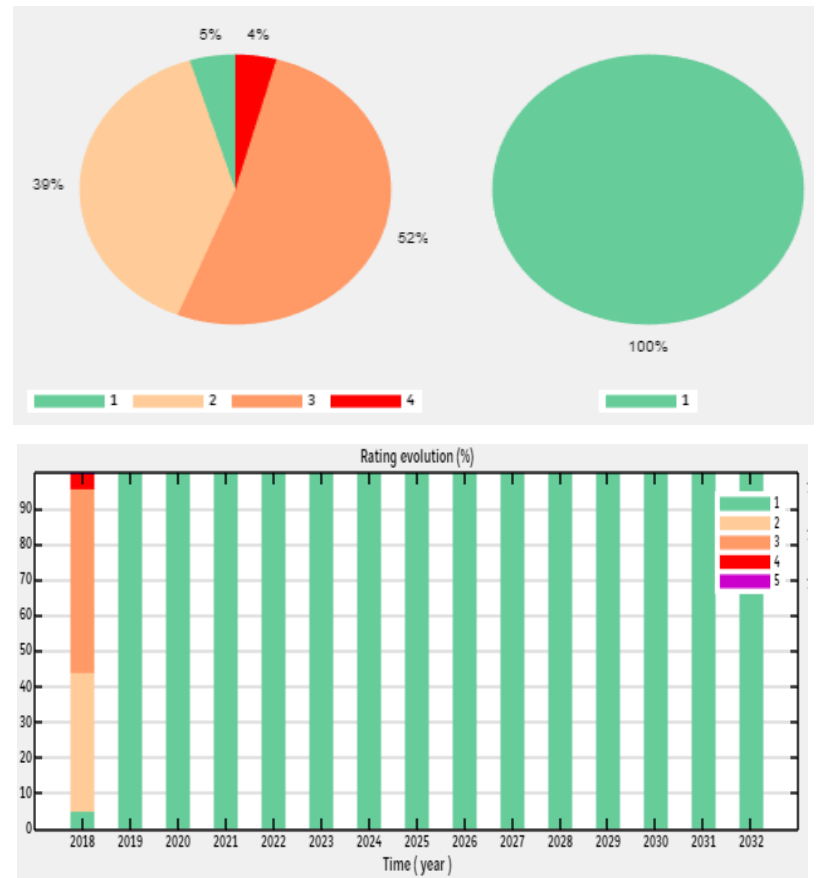

Fig. 11: Rating (\%) before and after simulation and Rating evolution

The total cost per year for maintenance is equal to $166 \mathrm{M} € /$ year and the average cost per $\mathrm{m}^{2}$ is equal to $387 € / \mathrm{m}^{2}$ (table 8 ). The average global rating goes from 2.57 to 1 (figure 11).

Table 8: Cost of maintenance per $m^{2}$ of deck for the six groups for predefined scenario 2

\begin{tabular}{|c|c|c|c|c|c|c|c|}
\hline & 1 & 2 & 3 & 4 & 5 & 6 & $\begin{array}{c}\text { Averag } \\
\mathrm{e}\end{array}$ \\
\hline $\begin{array}{l}\text { Cos } \\
\mathrm{t} \\
€ / \mathrm{m}\end{array}$ & 501 & $\begin{array}{c}44 \\
8\end{array}$ & 523 & 338 & 388 & 333 & 387 \\
\hline
\end{tabular}

\section{First problem to solve: Cost optimization}

To show the efficiency of our optimization algorithm, one propose to treat the "Keep all rating index constant scenario " and compare the results with those obtained in the table 7 . The target values $q_{\text {inf }}$ et $q_{\text {sup }}$ imposed to the optimization solver to keep the same rating are:

\begin{tabular}{|c|c|c|}
2 & $39.1 \%$ & $\mathrm{x}$ \\
3 & $\mathrm{x}$ & $51.5 \%$ \\
4 & $\mathrm{x}$ & $4.2 \%$ \\
5 & $\mathrm{x}$ & $0.5 \%$ \\
\hline
\end{tabular}
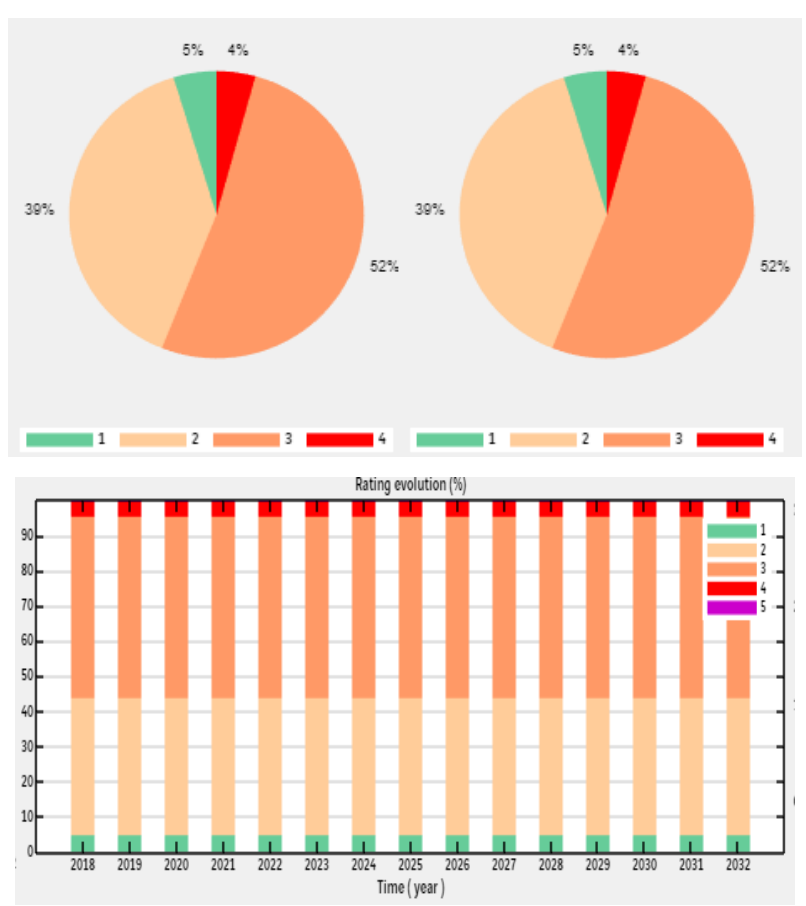

Fig. 12: Rating (\%) before and after simulation and Rating evolution

Figure 12 show the constant evolution of the fivecondition state.

Table 9: Cost of maintenance per $\mathrm{m}^{2}$ of deck for the six groups for optimized scenario 2

\begin{tabular}{|l|rrrrrrr|}
\hline & 1 & 2 & 3 & 4 & 5 & 6 & Average \\
\cline { 2 - 7 } Cost & & & & & & & \\
$€ / \mathrm{m}$ & 86 & 110 & 85 & 11 & 230 & 34 & 68.5 \\
\hline
\end{tabular}

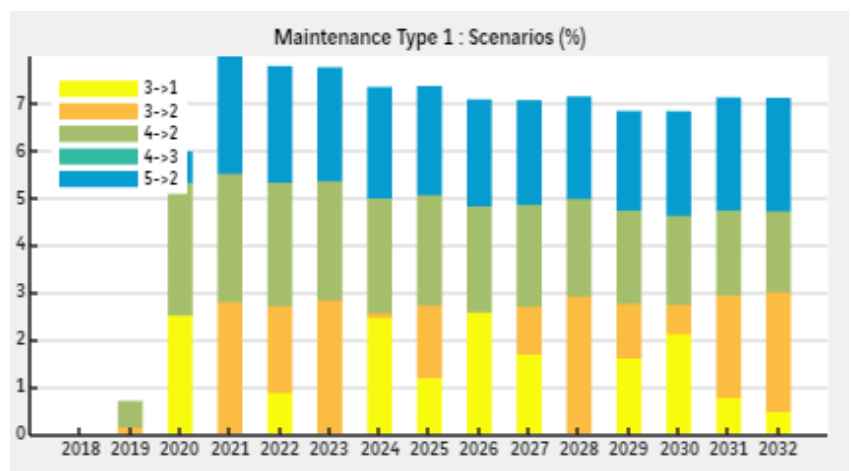

\begin{tabular}{|c|c|c|}
\hline Index & $q_{\text {inf }}$ & $q_{\text {sup }}$ \\
\hline 1 & $4.7 \%$ & $\mathrm{x}$ \\
\hline
\end{tabular}



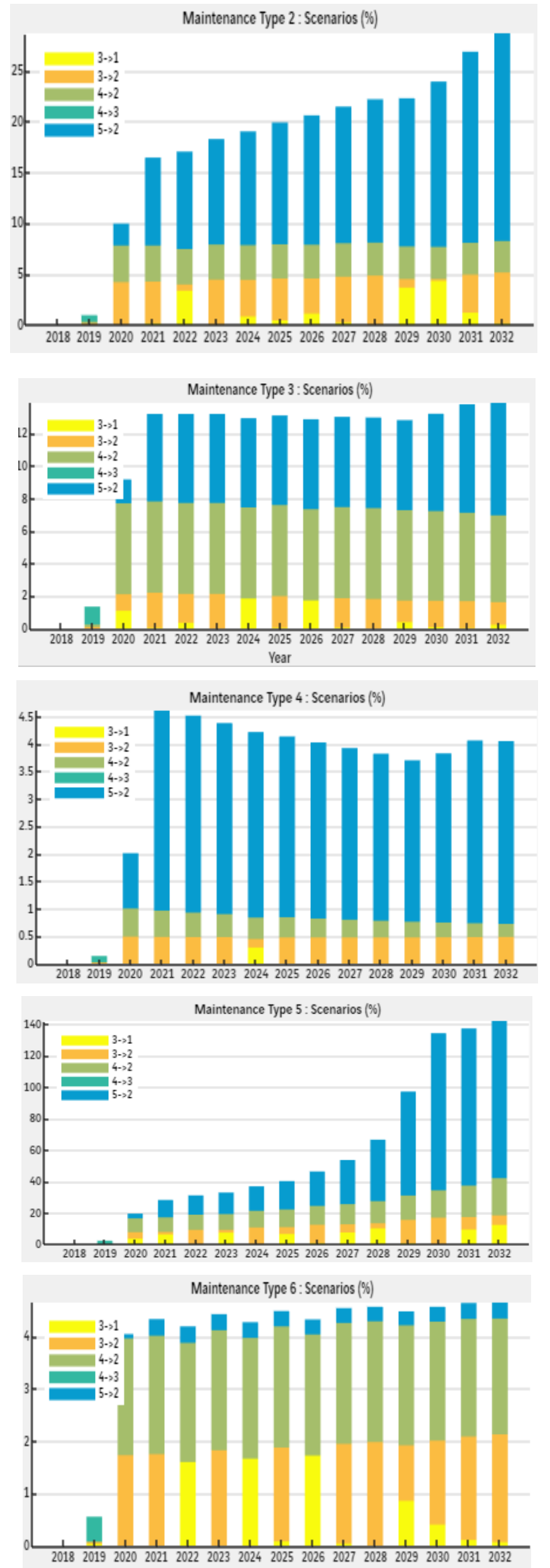

Fig. 13: Optimal maintenance cost for the six bridges group

The optimized scenarios for each bridges group are proposed in figure 13. For each bridges group, one finds in graphs' ordinates the percentage of surfaces which must be treated each year of simulation as well as the type of treatment. Notice that the goal is to find, for each group, the optimal variables values for the maintenance matrix [M].

$$
M=\left[\begin{array}{ccccc}
1 & 0 & 0 & 0 & 0 \\
x_{1} & 1-x_{1} & 0 & 0 & 0 \\
x_{2} & x_{3} & 1-x_{2}-x_{3} & 0 & 0 \\
x_{4} & x_{5} & x_{6} & 1-x_{4}-x_{5}-x_{6} & 0 \\
x_{7} & x_{8} & x_{9} & x_{10} & 1-x_{7}-x_{8}-x_{9}-x_{10}
\end{array}\right]
$$

For this specific case, to optimize the maintenance, the solver allocates null values to $\mathrm{x}_{4}$, $\mathrm{x}_{7}, \mathrm{x}_{9}$ and $\mathrm{x}_{10}$. The average cost weighted by the surface for all the groups is equal to $68.5 € / \mathrm{m}^{2}$ (table 8), therefore a gain of $18 \%$ is realized compared to result of the predefined scenario 2 (table 7). Notice that the CPU time spent for this simulation is equal to 120 seconds on an Intel Core i7 at 2.9Ghz 16 Go RAM.

\section{Second problem to solve: Quality optimization}

Another approach to test the robustness of the algorithm is to treat again the "Keep all rating index constant" scenario and impose its maintenance cost i.e. 35.9 M€/year over 15 years. The objective is to estimate the effect on the quality of the asset with this budget. In other words: how one improve the quality of the asset as much as possible by capping the budget to 35.9 $\mathrm{M} € /$ year knowing that with this budget and with scenario 2, the global indicator has remained constant? The answer to this question is given below (figure 14) and (table 10):
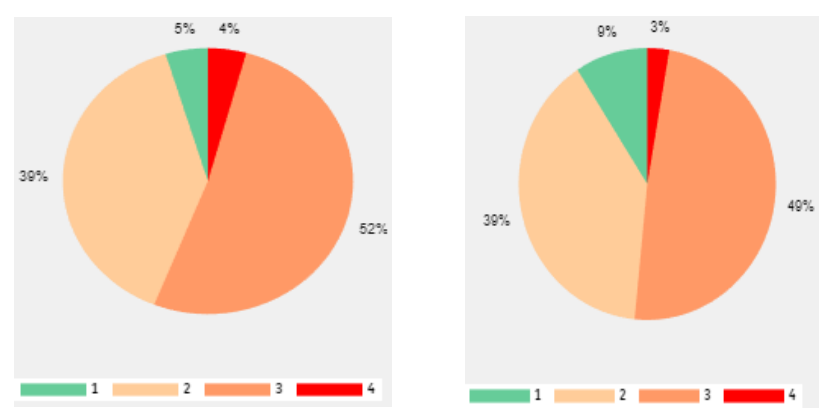


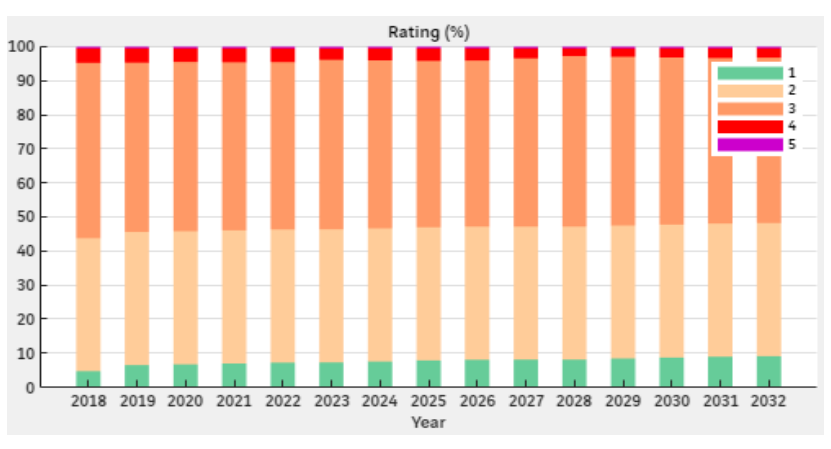

Fig. 14: Rating (\%) before and after simulation and Rating evolution

Table 10: Cost of maintenance per $m^{2}$ of deck for the six groups for optimized and scenario 2

\begin{tabular}{|c|cccccc|l|}
\hline $\begin{array}{c}\text { Cos } \\
\mathrm{t} \\
(€) /\end{array}$ & 1 & 2 & 3 & 4 & 5 & 6 & $\begin{array}{l}\text { Averag } \\
\mathrm{m}^{2}\end{array}$ \\
\cline { 1 - 5 } $\begin{array}{c}\text { Opti } \\
\mathrm{m}\end{array}$ & 147 & 60 & 135 & 89 & 74 & 46 & 83.7 \\
\cline { 1 - 1 } $\begin{array}{c}\text { Sce } \\
\mathrm{n} 2\end{array}$ & 72 & 76 & 115 & 72 & 100 & 94 & 83.7 \\
\hline
\end{tabular}

The average amount of maintenance work is the same as that of scenario 2 (table 9). This is equal to $83.7 € / \mathrm{m}^{2}$. This is normal since one imposed the same overall amount each year. By cons, the amount per group is different, which means that other scenarios were applied and that with the same amount, one can do better than keeping the rating indicators constant over time.
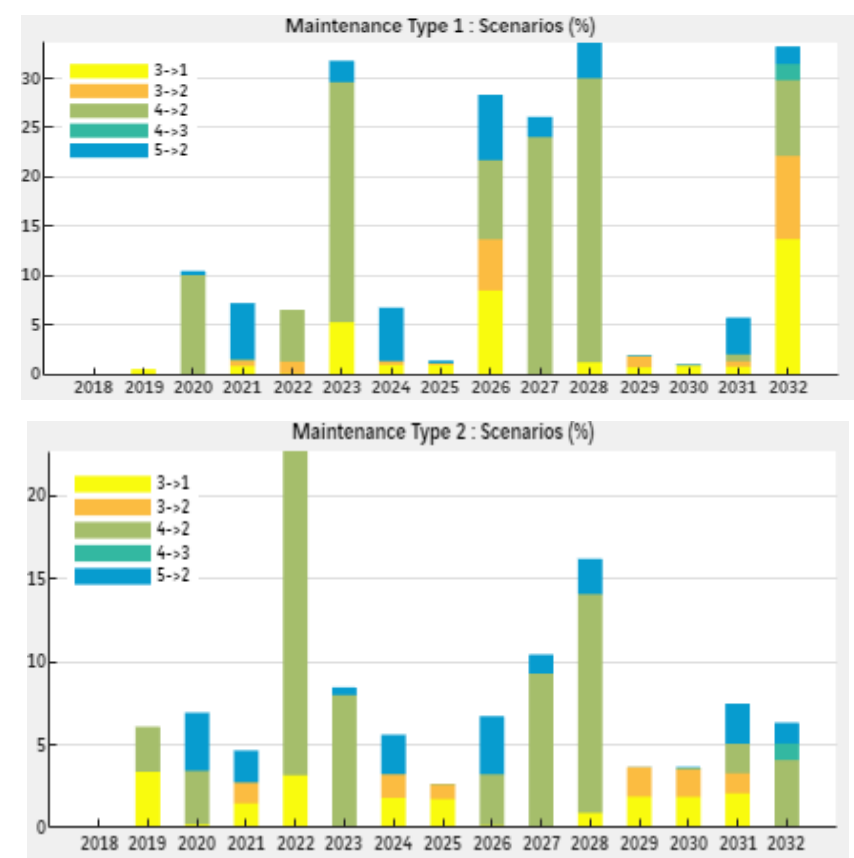
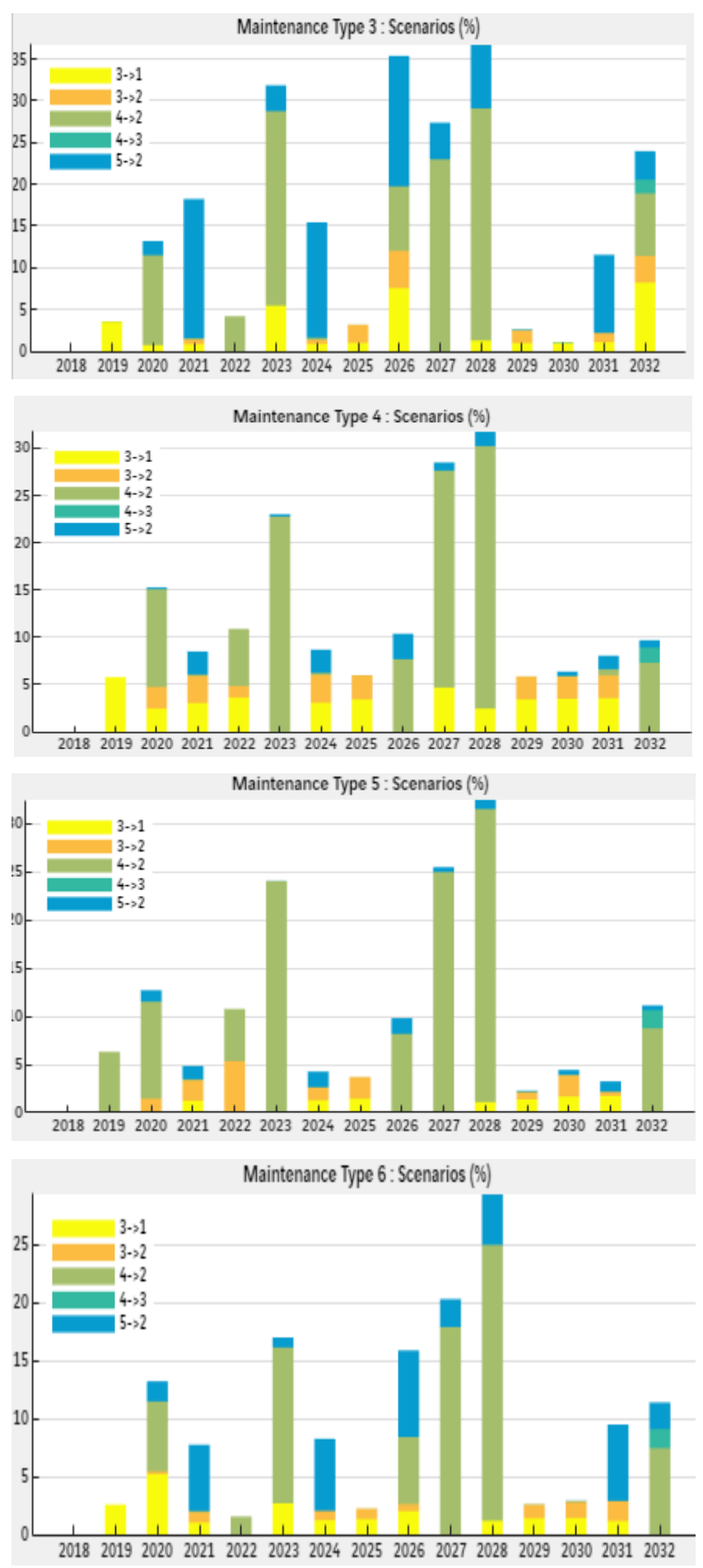

Fig. 15: Optimal maintenance for the six bridges groups

Figure 15 show the maintenance scenario for the six bridges group. The surfaces treated by year and by indices are presented on the ordinate. As in the previous case, the optimization algorithm is based on five maintenance possibilities to solve the problem. The five possibilities for moving surfaces are: 3 to 1,3 to 2,4 to 2,4 to 3 and 5 to 2 which corresponds to $\mathrm{x}_{1}, \mathrm{x}_{2}, \mathrm{x}_{3}, \mathrm{x}_{6}$ and $\mathrm{x}_{8}$ optimization variables in $[\mathrm{M}]$ matrix. 


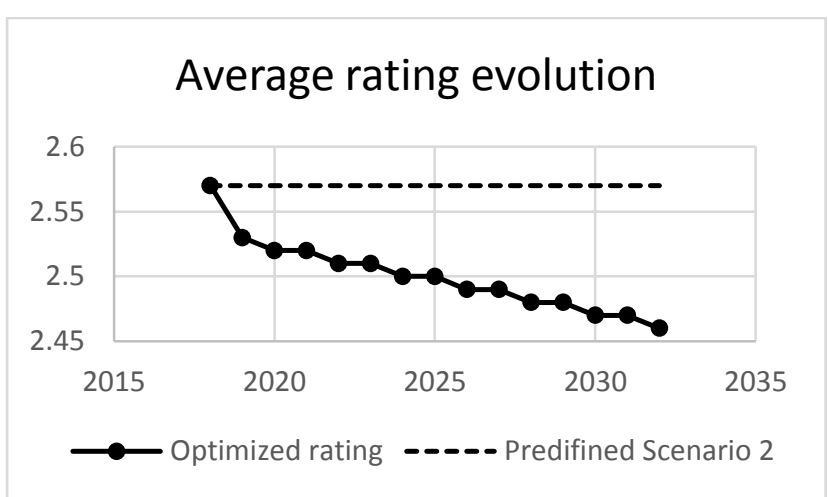

Fig. 16: Average rating for scenario 2 and optimized one

Figure 16 show the bridges quality improve with an imposed maintenance budget equal to the one of scenario 2. The improvement is estimate to $6 \%$ compared to the scenario 2. The CPU time spent for this simulation is equal to 180 seconds. An example of cost distribution per group is proposed in the following figure (figure 17):

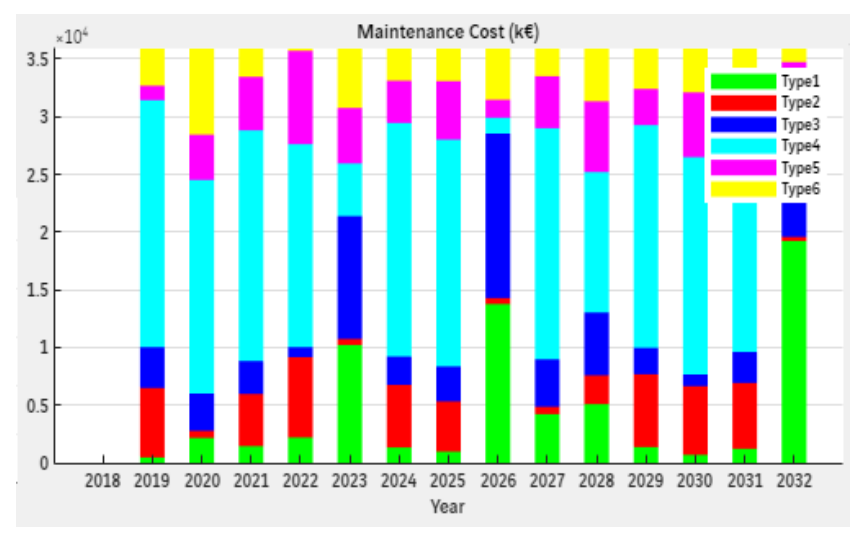

Fig. 17: Optimal maintenance cost per group or type

One observe for example that one spend more for group 4 (1858 bridges) even if their number is not the highest

\section{Conclusion}

In this study, we presented a new approach to program maintenance alternatives for a bridges network. The originality of this approach is the determination of the optimal scenarios through the maintenance matrix $[\mathrm{M}]$. For each bridges group, the ten optimization variables of this matrix represent the percentage of bridge deck areas passing from one condition state to another.

A Markov chain approaches will be considered to provide a means to achieve optimal budget allocation to better manage the bridge stock and optimize the performance levels for individual bridges. This approach uses genetic algorithm optimization techniques to resolve the optimization problem and the nonlinear Sequanciel Quadratic Programming (SQP) algorithm for determining the components of the transition matrix [P].

Data from the State of Indiana (14500 bridges) were used to develop six transition probability matrices that represent the deterioration of structural and material bridge categories (concrete, concrete-continuous, steel, steel-continuous, prestressed and prestressed-continuous). This application can be considered as a powerful financial tool for decision support and very efficient in terms of calculation time (less than 3 minutes for a park of 15,000 bridges).

\section{Data Availability Statement}

Federal Highway Administration (FHWA) https://www.fhwa.dot.gov/bridge/nbi/ascii.cfm

\section{References}

[1.] Agrawal, A. K., Kawaguchi, A., and Chen, Z. 2009. Bridge element deterioration rates, Rep. No. C-01-51, New York State DOT, Albany, NY.

[2.] A. Butt, M. Y. Shahin, K. J. Feighan, and S. H. Carpenter. 1987. Pavement performance prediction model using the Markov process, Transportation Research Record, pp. 12-19.

[3.] M. Cesare, C. Santamarina, C. Turkstra, and E. Vanmarcke. 1992. Modeling bridge deterioration with Markov chains, Journal of Transportation Engineering, vol. 118, no. 6 , pp. $820-833$.

[4.] H. Elbehairy. 2007. Bridge management system with integrated life cycle cost optimization, University of Waterloo. Ph.D. thesis, Ontario, Canada.

[5.] Reginald W. Stratt. 2010. Bridge Management a System Approach for Decision Making, PhD thesis, Department of Engineering and Technology in the School of Doctoral Studies of the EU, Belgium.

[6.] G. Morcous, Z. Lounis. 2005. Maintenance optimization of infrastructure networks using genetic algorithms, Automation in Construction, 14 129-142

[7.] G. Morcous. 2006. Performance prediction of bridge deck systems using Markov Chains, Journal of Performance of 
Constructed Facilities, American Society of Civil Engineers, vol. 20, No. 2.

[8.] Milhan Moomen, Yu Qiao, Bismark R. Agbelie, Samuel Labi, Kumares C. Sinha. 2016. Bridge Deterioration Models to Support Indiana's Bridge Management System, Report Number: FHWA/IN/JTRP

[9.] Niroshan K. Walgama Wellalage; Tieling Zhang and Richard Dwight. 2015. Calibrating Markov Chain-Based Deterioration Models for Predicting Future Conditions of Railway Bridge Elements, J. Bridge Eng.

[10.] J. Yi, M. Saito, and K. C. Sinha. 1988. Bridge performance prediction model using the Markov chain Transportation Research Record, Transportation Research Record, no. 1180, pp. 25-32.

[11.] O. S. Thomas and J. O. Sobanjo. 2016. Semi-Markov Decision Process: A Decision Tool for Transportation Infrastructure Management Systems, International Conference on Transportation and Development.

[12.] Paul D. Thompson, Kevin M. Ford, Mohammad H. R. Arman, Samuel Labi, Kumares C. Sinha, and Arun M. Shirole. 2007. Estimating Life Expectancies of Highway Assets, NCHRP report 713

[13.] Vandana Patidar, Samuel Labi, Kumares C. Sinha, Paul Thompson. 2007. Multi-
Objective Optimization for Bridge Management Systems, NCHRP report 590.

\section{Author Profile}

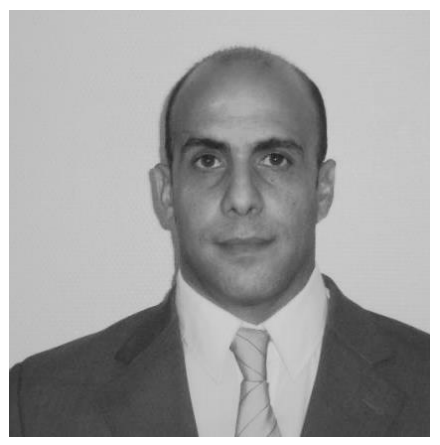

\section{Sofiane Hadji}

Scientific Director in Civil and Environmental Technology at SIXENSE Engineering (Vinci Group) in France since 2010. Dr. Hadji received (1995) his Ph.D. degree in Mechanical engineering (Modeling \& Optimization of Products \& Structures) and his Maters Engineering Science degree (1991) from the UTC. He also obtained (1990) his B.Eng degree in Civil Engineering from the University of Algiers in Algeria. His research interests include Computational Civil Engineering, Free Surface Water Modeling, Optimization methods. To date, he authored more than 60 technical reports and 20 international journal papers. 